\title{
Comparative life tables of leek moth, Acrolepiopsis assectella (Zeller) (Lepidoptera: Acrolepiidae), in its native range
}

\author{
W.H. Jenner ${ }^{1 * \dagger}$, U. Kuhlmann ${ }^{2}$, P.G. Mason ${ }^{3}$ \\ and N. Cappuccino ${ }^{1}$ \\ ${ }^{1}$ Department of Biology, Carleton University, 1125 Colonel By Drive, \\ Ottawa, ON, K1S 5B6, Canada: ${ }^{2}$ CABI Europe - Switzerland, 1 Rue des \\ Grillons, Delémont, CH-2800, Switzerland: ${ }^{3}$ Eastern Cereal and Oilseed \\ Research Centre, Agriculture and Agri-Food Canada, 960 Carling Avenue, \\ Ottawa, ON, K1A 0C6
}

\begin{abstract}
Leek moth, Acrolepiopsis assectella (Zeller) (Lepidoptera: Acrolepiidae), is an invasive alien species in eastern Canada, the larvae of which mine the green tissues of Allium spp. This study was designed to construct and analyse life tables for leek moth within its native range. Stage-specific mortality rates were estimated for the third leek moth generation at three sites in Switzerland from 2004 to 2006 to identify some of the principle factors that inhibit leek moth population growth in areas of low pest density. The contribution of natural enemies to leek moth mortality was measured by comparing mortality on caged and uncaged leeks. Total pre-imaginal mortality on uncaged plants was $99.6 \%, 99.1 \%$ and $96.4 \%$ in 2004, 2005 and 2006, respectively. Variation in mortality was greater among years than among sites. Total larval mortality was greater than that in the eggs and pupae. This was due largely to the high mortality (up to 83.3\%) of neonates during the brief period between egg hatch and establishment of the feeding mine. Leek moth pupal mortality was significantly greater on uncaged than on caged leeks, indicating an impact by natural enemies, and this pattern was consistent over all three years of study. In contrast, the other life stages did not show consistently higher mortality rates on uncaged plants. This observation suggests that the pupal stage may be particularly vulnerable to natural enemies and, therefore, may be the best target for classical biological control in Canada.
\end{abstract}

Keywords: Acrolepiopsis assectella, exclusion, fecundity, key factor, life table, stage-specific mortality, natural enemy impact

(Accepted 15 January 2009)

*Author for correspondence

Fax: +41-32-421-4871

E-mail: w.jenner@cabi.org

${ }^{\dagger}$ Current address: CABI Europe - Switzerland, 1 Rue des

Grillons, Delémont, CH-2800, Switzerland

\section{Introduction}

The leek moth, Acrolepiopsis assectella (Zeller) (Lepidoptera: Acrolepiidae), is a widely distributed, multivoltine pest of Allium spp. (Asparagales: Alliaceae) in Europe (Jary \& Rolfe, 1945; Frediani, 1954; Markula, 1981), Asia 
(Velitchkevitch, 1924) and North Africa (Labeyrie, 1966). Without appropriate control measures, the effects of leek moth on Allium production can be devastating (e.g. Plaskota \& Dabrowski, 1986; Nyrop et al., 1989), leading to heavy loss of vegetable and seed products. The larvae are concealed feeders, mining primarily in the leaves and stems of their host plants, but damaging flower buds and even the bulbs under extreme circumstances (Noyes, 1974). Leek moth is best known for its impact on leek production but also commonly attacks onion, shallot, garlic and chive. Following its unintentional introduction into North America and discovery in 1993 (Landry, 2007), leek moth has established itself as a pest of concern in Allium production in eastern Ontario and western Quebec. Because the leek moth is a quarantine pest in the US, where, as of early 2008, it had not yet been detected, the cross-border movement of Allium products has been partially disrupted (M.-P. Mignault, Canadian Food Inspection Agency, personal communication). In addition to its effects on agriculture, leek moth may pose a threat to North American Allium biodiversity. In a recent study, Allison et al. (2007) demonstrated that rare wild Allium species stimulate leek moth oviposition and can support larval development.

Pheromone trap data from the Ottawa, Ontario region showed population levels up to ten times greater than at sites simultaneously sampled in Switzerland, within its area of origin (Mason et al., 2006; Jenner \& Kuhlmann, 2005). This commonly seen disjuncture of pest densities between areas of origin and introduction is often ascribed to the enemy-release hypothesis, whereby introduced species experience increased abundance due to the failure of their co-evolved natural enemies to follow them to the new range (Elton, 1958; Debach \& Rosen, 1991; Van Driesche \& Bellows, 1996). This hypothesis is built on the foundation that a pest is controlled, at least in part, by a natural enemy community in its area of origin. It, therefore, follows that assessments of these predator and parasitoid assemblages may lead to the identification of suitable biological control agents.

Exploration for candidate classical biological control agents for leek moth was initiated in 2004. In the same year, the current study was launched to identify principle factors that inhibit leek moth population growth in areas of low pest density in central Europe. The specific aim of this study was to build and analyse life tables for leek moth over multiple years in its area of origin to identify key stages of mortality. In addition to quantifying mortality in the 'traditional' insect life stages (i.e. egg, larva and pupa), this study attempts to shed more light on the subject of posthatch mortality and the factors behind it by measuring the rate of successful establishment of newly eclosed first instar larvae. Although leek moth larvae feed internally, much of the life cycle occurs outside the host plant. Eggs are laid superficially and, prior to pupation, final instar larvae abandon their feeding galleries to spin a cocoon on the outside of the plant. In their comparisons of pre-adult survival in endophytic and exophytic species, Price (1975) and Cornell \& Hawkins (1995) observed a trend for greater enemy-induced mortality in the latter, presumably because exophytic species are more apparent and lack the protection of a physical refuge. For the same reasons, we anticipated that leek moth field mortality would be greater in the exposed egg and pupal stages than in the concealed larval instars.

\section{Materials and methods}

Site preparation

The three-year life table study was conducted in commercial organic and integrated production leek fields between 2004 and 2006. In each year, leek moth mortality was measured simultaneously at three field sites, each from one of three regions in Switzerland. Site A (near Bern, western Switzerland $\mathrm{N} 46^{\circ} 59.488^{\prime}$ E7 $\left.7.685^{\prime}\right)$ was approximately $120 \mathrm{~km}$ southwest of site B (near Zurich, north central Switzerland, $\mathrm{N} 47^{\circ} 31.100^{\prime} \mathrm{E}^{\circ} 28.521^{\prime}$ ), which in turn was approximately $55 \mathrm{~km}$ southwest of site C (near Konstanz, northeastern Switzerland N47 39.003 E9 $\left.9^{\circ} .131^{\prime}\right)$. Five sampling blocks $(3 \times 2 \mathrm{~m})$ were set up at each field site, two in the crop centre and three along the field margins. For each leek moth life stage, there were six infested leeks in all five blocks (=30 sampled leeks per field per life stage). The quality of test plants was standardised between sites and years by consistently using the summer leek variety 'Hilari', the seedlings of which were always purchased from the same producer (Hans Etter-Bangerter, Gemüse \& Jungpflanzen). The leeks were potted individually and grown inside field cages at the CABI Europe-Switzerland Centre. These plants were then infested and inserted among the commercial leeks in each block.

Leek moth undergoes three generations annually in Switzerland. As it was not feasible to conduct a life table study over all three generations for three years, we chose to focus on the final generation, which was expected to have the greatest natural enemy impact (Plaskota \& Dabrowski, 1986). The life table study commenced when pheromone trap counts indicated the start of the third generation.

\section{Stage-specific mortality}

Although leek moth adults were caught in pheromone traps at all sampling sites, the natural populations were generally too low to even detect infestation. Hence, we evaluated field mortality using artificial populations. This manipulative approach enabled us to standardise the age and density of insects placed on each plant in the field at a given time. A leek moth culture was established using larvae and pupae collected in leek and chive fields in west-central Switzerland. In the laboratory, the colony was reared on leeks at $20 \pm 3^{\circ} \mathrm{C}$ and 16L:8D. Leek moth specimens were then transferred to the field once they had reached the desired life stage. The pre-imaginal stages were set out in the field in a sequential fashion, beginning with the egg stage, and were timed to match the phenology of natural leek moth populations, using pheromone trap data. Each developmental stage was exposed in the experimental blocks for only the duration of that stage. The aim was to retrieve the immature leek moths from the field just prior to eclosion (eggs and pupae) or during moulting (larvae). The duration of field exposure for a particular life stage was determined by closely monitoring the development of a subset of individuals, held outside at the CABI Centre. The developmental rate of leek moths in late summer was similar among the three field sites and the CABI Centre. The sentinel leek moths were retrieved from the field when the monitored subset reached the end of its current life stage. The infested leeks were also used only once.

Leek moth eggs were obtained by motivating adult moths to oviposit on 'egg strips', strips of stiff, smooth, green 
plastic. Pieces of crushed leek leaf were rubbed over the surface of the egg strips, which were then placed into a cage overnight with hundreds of adult moths. The next morning, the egg strips were removed from the adult cage and cut into smaller pieces (approximately $2 \mathrm{~cm}^{2}$ ) containing 10-20 eggs. All malformed eggs were removed. These egg batches were then taken immediately to the field sites and attached, one per plant, to leeks within the blocks. To mimic a natural distribution of leek moth eggs according to Noyes (1974), most egg strips were pinned to the ventral side of the lower leaves with a smaller portion allocated to dorsal surfaces and upper leaves. Upon recovery from the field, the eggs were brought back to the laboratory to observe egg hatch and record survival.

To measure mortality during the neonate establishment phase, a second cohort of eggs was placed in the field as explained above, but with one difference: instead of retrieving these egg strips just prior to egg hatch, they were left in the field for extra time to allow for egg hatch and the subsequent entry of neonate larvae into the leek leaves. These infested leeks were then retrieved and dissected in the laboratory to count the number of first instar larvae that had managed to establish on each plant. Post-hatch mortality was calculated by dividing the number of successfully established neonate larvae by the number of hatched eggs. Henceforth, the use of 'neonate' will refer strictly to the pre-feeding phase of wandering and leaf penetration by newly hatched larvae.

The five larval instars were placed in the field sequentially following the egg stage. As the sentinel eggs were recovered from the experimental blocks, they were replaced immediately with first instar larvae. Similarly, when the first instar larvae were removed, the second instar exposure began. This swapping of subsequent life stages continued until the end of the pupal stage. To prepare the first instar cohort, newly eclosed larvae ( $<2$ min since hatch) were transferred directly onto healthy potted leeks. Cohorts of the second, third, fourth and fifth instars were prepared for field exposure in precisely the same way except that they had to be dissected from their feeding mines before being transferred to the experimental leeks. Only larvae that had recently moulted to the instar of interest, identified by colour and relative size of the head capsule, were used for the life table study. The larval density per plant for each instar was: five first instars, five second instars, four third instars, three fourth instars and three fifth instars. Since leek moth larvae commonly abandon their mines to find new feeding sites, it was not unnatural to have them establish new mines prior to the field experiment. The transferring of larvae to potted leeks was always done in the laboratory late in the evening, giving the larvae several hours to safely establish feeding mines before the leeks were taken to the field sites the next morning. The infested potted leeks were inserted into the experimental blocks among the field leeks and the bases of the pots were dug at least $5 \mathrm{~cm}$ into the soil. In addition, any leaves from surrounding plants that were touching the sentinel potted leeks were clipped to reduce the likelihood of larvae walking off the experimental plants. Each larval instar was left in the field for as many days as necessary to reach the next moult. Retrieving the sentinel larvae consisted of transporting the potted leeks back to the laboratory where they were dissected to obtain all remaining specimens. The surviving individuals were reared on sections of leek leaves in labelled
Petri dishes (9 $\mathrm{cm}$ dia., $2 \mathrm{~cm}$ depth) to record the emergence of parasitoids.

Mortality in the final immature stage was measured by attaching leek moth cocoons, two per plant, to leeks within the field blocks. The cocoons were collected from the laboratory culture in the morning and taken immediately to the three field sites. Fine insect pins (00 and 000) were used to attach the cocoons to random places on the assigned leeks since leek moth is known to pupate on all parts of the plant (Thibout \& Nowbahari, 1987). Preliminary trials had shown that pinning cocoons to leaves had no effect on leek moth survival or oviposition success by parasitoids. As these cocoons were less than $24 \mathrm{~h}$ old, they all contained a prepupa, which then pupated at some point during the first or second day in the field, depending on temperature. This life stage, hereafter called 'pupa', therefore, actually includes mortality inflicted during both the pre-pupal and pupal phases. The pupae were retrieved from the field as close to adult eclosion as possible and brought to the laboratory to assess mortality.

\section{Natural enemy impact}

In addition to calculating stage-specific field mortality rates, an exclusion technique was used to evaluate the effect of predators and parasitiods on leek moth survival. For each life stage, all blocks within the three sites were assigned three control (caged) plants and three treatment (exposed) plants. Following infestation with sentinel leek moth individuals, the control leeks were covered with finely woven muslin bags ( $0.3 \mathrm{~mm}$ space between threads), which were supported around each plant by a single, parabolicshaped wire frame. At the base of the plants, the muslin bags were dug into the soil to completely block access by macroscopic arthropod and vertebrate natural enemies. In contrast, the uncovered plants were fully exposed to all biotic mortality factors. Estimation of impact by natural enemies was done by comparing mortality between caged and exposed leeks.

\section{Potential and realised fecundity}

To construct complete life tables, it was necessary to estimate the fecundity of leek moth females. At the same time that leek moth eggs were placed in the field, oviposition trials were conducted to measure both potential and realised lifetime fecundity. The potential fecundity was determined by placing a newly emerged male and female pair into a Petri dish ( $9 \mathrm{~cm}$ dia., $2 \mathrm{~cm}$ depth) containing a freshly cut leek leaf disc and a piece of dental cotton soaked in a $20 \%$ sucrose solution. The oviposition arenas were kept at $21 \pm 2^{\circ} \mathrm{C}$ and 16L:8D. All eggs laid in the Petri dish were counted every two to three days, at which time the moth pair was transferred to a new Petri dish with a new leaf disc and cotton bud. A total of 50, 15 and 23 moth pairs were tested in 2004, 2005 and 2006, respectively.

Realised fecundity was measured in 2005 and 2006 by enclosing male-female pairs with small potted leeks, which were then placed along field margins at the three field sites. These experimental leeks were framed by two perpendicular, parabolic-shaped wires and covered with finely woven muslin bags $(0.3 \mathrm{~mm}$ space between threads), which were sealed around the base of the pot with elastic bands. These exclusion cages prevented access to the moths by natural 
enemies, but exposed the moths to natural light, moisture and temperature levels. Every 3-5 days, the moth pairs were transferred to a fresh potted leek and the eggs laid during the previous days were counted. A total of 30, 32 and 25 moth pairs were tested in 2004, 2005 and 2006, respectively. All fecundity trials continued until the death of the female.

\section{Construction of life tables}

The field mortality data were used to construct survivorship curves and life tables for each year of the study. Whereas the mortality probability for each life stage was calculated from a fresh cohort of a pre-determined number of leek moths, the life tables were constructed in a more longitudinal fashion, with a standardised starting number of 1000 eggs to effectively illustrate accumulated mortality.

Since the study design consisted of five discrete sampling blocks per site, these blocks were treated as cluster samples. Mean mortality rates were calculated from the three caged and three exposed leeks in each block. Hence, each field site had five data points for both the caged and exposed treatments. Apparent mortality $\left(q_{x}\right)$ is the ratio of the number dying $\left(d_{x}\right)$ in stage $x$ to the number entering $\left(l_{x}\right)$ that same stage. When multiple mortality factors act simultaneously, the marginal attack rate $\left(m_{x}\right)$ is a useful measure because it calculates the proportion of individuals of a particular stage that would be killed by a single factor if it were acting alone (Bellows et al., 1992). If there is only one identified mortality factor or if the multiple mortality factors operate sequentially without overlap, then the marginal death rate will equal apparent mortality. When factors operate contemporaneously and there is no information on interactions between those factors, the marginal death rate is calculated as: $m_{x}=1-(1-q)^{q i / q}$, where $q_{i}$ is the apparent mortality caused by the $i$ th factor while $q$ is the stage mortality rate caused by all factors (Elkinton et al., 1992).

The outcome of a life table can be expressed as the mean realised progeny of a population (i.e. the mean realised lifetime fecundity multiplied by the number of surviving females). A sex ratio of 1:1 was assumed (Noyes, 1974). Lost fertility, potential minus realised fecundity, was incorporated into the life tables to account for the impact that incomplete egg laying has on population change. The inclusion of fecundity estimates is important because it permits calculation of net reproductive rate $\left(R_{0}=\right.$ number of female offspring from a single reproductive female).

\section{Key factor analysis}

Once marginal death rates were determined, $k$-values, calculated as the difference between logarithms of $l_{x}$ before and after the action of each mortality factor (Varley \& Gradwell, 1960), were assigned to each mortality factor. This facilitated measuring the contribution of each $k$-value to the generational, or total, mortality $(K)$, which is the sum of all $k$-values in a life table. The $k$-values were additionally used to identify the key mortality factors that appear to be largely responsible for changes in population density (Morris, 1959). We first applied the method described by Varley \& Gradwell (1960), where the total mortality and stage-specific $k$-values were plotted for a set of nine consecutive life tables (three life tables $\times$ three years). The $k$-value that best tracks total mortality is said to be the key factor. Second, we made a series of regressions of each $k$-value sequence against $K$. The

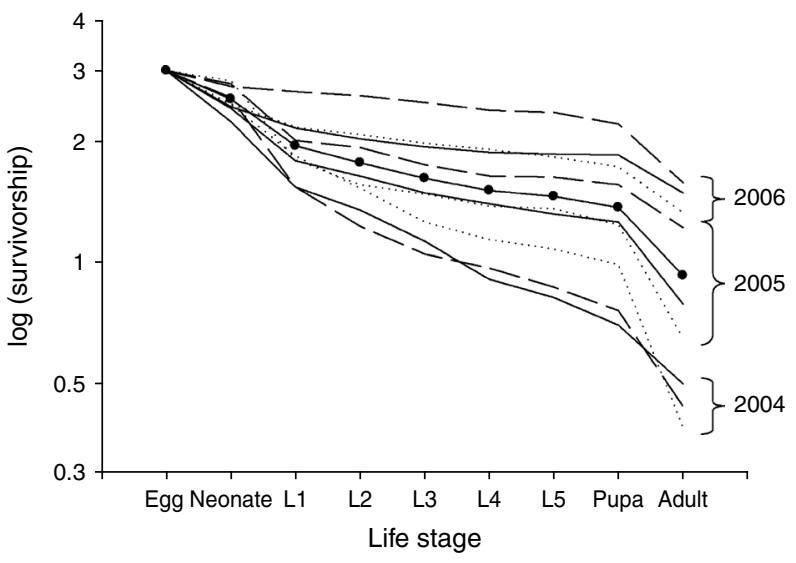

Fig. 1. Survivorship curves for immature Acrolepiopsis assectella at three commercial leek production sites from 2004 to 2006 (thin solid lines, site A; dashed lines, site B; dotted lines, site C; solid line with circular symbols, mean survivorship).

individual $k$-value that gave the greatest slope, while maintaining a significant correlation to $K$, was recognised as the key factor (Podoler \& Rogers, 1975). While the five larval instars are shown separately in the life tables below, they were pooled for the key factor analysis by taking the sum of their $k$-values.

\section{Data analyses}

All statistical analyses were carried out on arcsine square root transformed data using SPSS version 14.0 (SPSS Inc, Chicago, IL). Linear regression analysis was used to test for a correlation between total pre-imaginal development time (exposure duration) and total mortality. Stage-specific mortality rates within each year and female fecundities were compared using one-way ANOVA, and the means were separated using the Tukey HSD test. Several of the paired data sets from the exclusion experiment did not fit a normal distribution following transformation; therefore, the comparison of mortality under caged and exposed conditions for each life stage was performed with Wilcoxon paired-sample tests. The significance level was set at $\alpha=0.05$ and all data presented in the tables, figures and text, unless stated otherwise, are untransformed means.

\section{Results \\ Stage-specific mortality}

Figure 1 shows survivorship curves that were generated for each site from 2004 to 2006 and exhibits a relative consistency in leek moth attrition, with the greatest variation occurring in egg, neonate and pupal mortality. Complete life tables giving stage-specific mortality rates for each year are presented in tables 1-3 (based on uncaged leeks only). Total mortality and fecundity values for each year are derived from three life tables representing the three field sites (data are pooled, site-specific tables are not shown). Total mortality of the immature stages varied only slightly between $2004(99.6 \%)$ and 2005 (99.1\%), but dropped significantly in 2006 (96.4\%). This change was driven mainly by site $B$, which exhibited the most striking increase in 
Table 1. Life table for the third generation of leek moth, Acrolepiopsis assectella. Data are pooled from three sites in Switzerland in 2004.

\begin{tabular}{|c|c|c|c|c|c|c|c|}
\hline Life stage & $\begin{array}{l}\text { Mortality } \\
\text { factor }\end{array}$ & $l_{x}$ & $d_{x}$ & $100 q_{x}$ & $m_{x}$ & $k$-value & $\begin{array}{l}\% \text { generational } \\
\text { mortality }\end{array}$ \\
\hline Eggs & Unknown & 1000.0 & 720.0 & 72.0 & 72.0 & 0.553 & 16.9 \\
\hline Neonate & Unknown & 280.0 & 230.2 & 82.2 & 82.2 & 0.750 & 22.9 \\
\hline \multirow[t]{2}{*}{ L2 } & Unknown & 26.8 & 10.8 & 40.0 & 40.0 & 0.222 & 6.8 \\
\hline & Parasitoid & 16.1 & 0.1 & 0.4 & 0.5 & 0.002 & 0.1 \\
\hline L3 & Unknown & 16.0 & 4.4 & 27.2 & 27.2 & 0.138 & 4.2 \\
\hline L5 & Unknown & 9.6 & 2.1 & 21.9 & 21.9 & 0.107 & 3.3 \\
\hline Pupae & Unknown & 7.5 & 3.9 & 51.3 & 51.3 & 0.312 & 9.5 \\
\hline Adults emerged & Sex ratio & 3.7 & 1.8 & 50.0 & 50.0 & 0.301 & 9.2 \\
\hline Adult females & & 1.8 & & & & & \\
\hline Potential progeny* & Lost fertility & 640.6 & 455.7 & 71.1 & 71.1 & 0.540 & 16.5 \\
\hline Realised progeny** & & 184.9 & & & & & \\
\hline
\end{tabular}

* Potential progeny $=(\#$ of surviving females $) \times($ mean potential fecundity from 2004$)$.

** Realised progeny $=(\#$ of surviving females $) \times($ mean realised fecundity from 2004$)$.

$l_{x}$, number entering stage; $d_{x}$, number dying in stage; $q_{x}$, apparent mortality; $m_{x}$, marginal mortality.

Table 2. Life table for the third generation of leek moth, Acrolepiopsis assectella. Data are pooled from three sites in Switzerland in 2005.

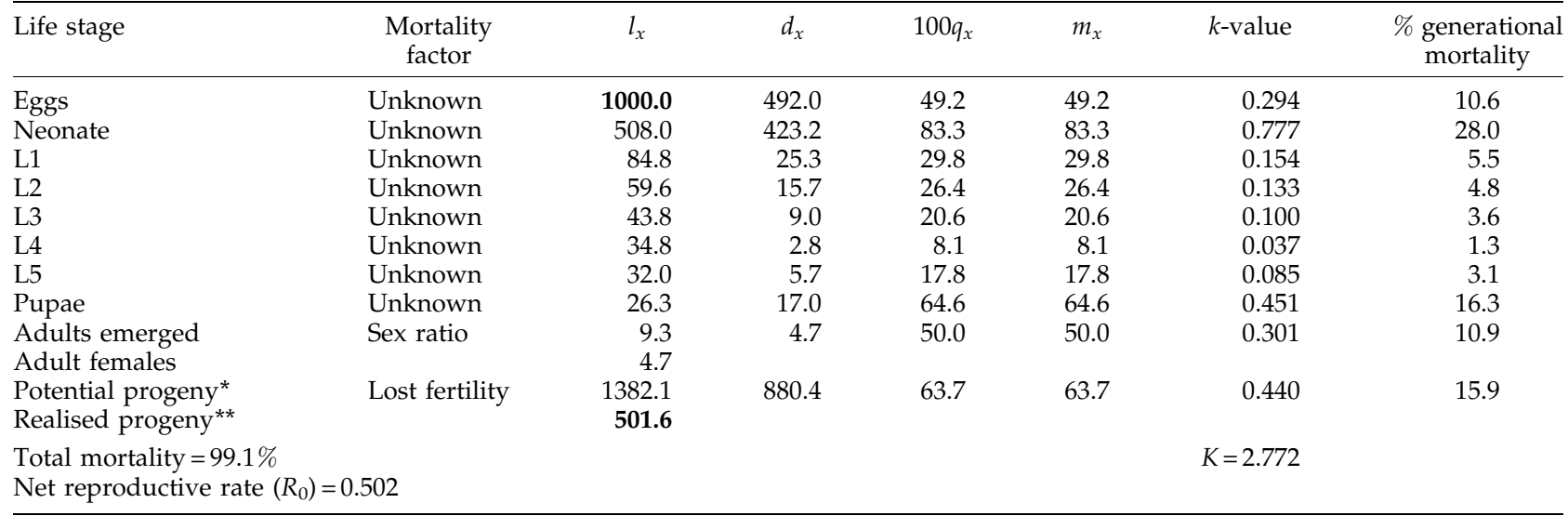

* Potential progeny $=(\#$ of surviving females $) \times($ mean potential fecundity from 2005).

** Realised progeny $=(\#$ of surviving females $) \times($ mean realised fecundity from 2005$)$.

$l_{x}$, number entering stage; $d_{x}$, number dying in stage; $q_{x}$, apparent mortality; $m_{x}$, marginal mortality.

pre-imaginal survivorship. Nonetheless, all three sites had lower total mortality in 2006, and it is attributed primarily to higher survival during neonate establishment that year. For instance, the three highest survivorship curves in fig. 1 are all from 2006. Inter-site variation was greatest in 2005. Site $C$ had the highest total mortality rates in all years of the study, whereas site B had the lowest values in 2005 and 2006.

During the course of leek moth development, there were significant differences in stage-specific mortality rates (2004: $\mathrm{F}=21.83, P<0.001 ; 2005: \mathrm{F}=43.65, P<0.001 ; 2006: \mathrm{F}=21.00$, $P<0.001)$. In all years of the study, mortality was greatest during the egg, neonate and pupal phases but low for individual larval instars. Egg mortality ranged from 50-70\% and was a consistent key contributor to generational mortality. In both 2004 and 2005, neonate mortality contributed strongly to generational mortality $(22.9 \%$ and $28.0 \%$, respectively); but, as mentioned earlier, this stage suffered less mortality in 2006 (only 9.7\% of generational mortality). Neonate mortality was significantly higher than egg mortality in 2005, but was not significantly different in 2004 and 2006. On an instar-by-instar basis, leek moth larvae appeared to be less vulnerable to mortality factors. It was extremely rare in any of the nine site-specific life tables for mortality in a particular larval instar to surpass that of the non-feeding stages. Among the larval stages, mortality was highest in the early instars. The means for larval mortality averaged over all sites and years are as follows: $\mathrm{L} 1=31.6 \%$; L2 $=29.0 \% ; \quad \mathrm{L} 3=21.9 \% ; \mathrm{L} 4=11.3 \% ; \mathrm{L} 5=19.2 \%$. When all instars are combined, total larval mortality was $84.9 \%$, 
Table 3. Life table for the third generation of leek moth, Acrolepiopsis assectella. Data are pooled from three sites in Switzerland in 2006.

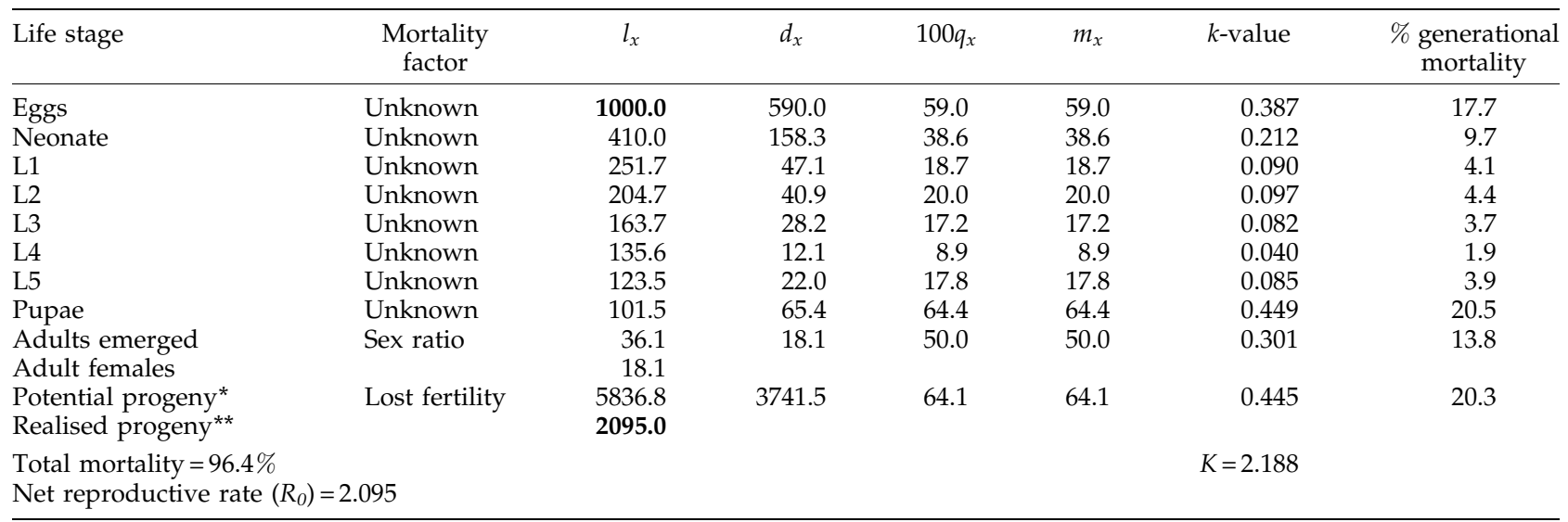

* Potential progeny $=(\#$ of surviving females $) \times($ mean potential fecundity from 2006$)$.

** Realised progeny $=(\#$ of surviving females $) \times($ mean realised fecundity from 2006).

$l_{x}$, number entering stage; $d_{x}$, number dying in stage; $q_{x}$, apparent mortality; $m_{x}$, marginal mortality.

$69.0 \%$ and $59.7 \%$ in 2004, 2005 and 2006, respectively. These mortality rates translate to $25.0 \%, 18.4 \%$ and $18.0 \%$ of generational mortality in each of those years, respectively, and thus make larval death one of the greatest contributors to immature mortality. On average, larval mortality showed a decreasing trend over the three years of the study. In contrast, mortality of pupae gave the opposite response, such that it contributed twice as much to generational mortality in 2006 than in 2004. Due to this increase in pupal mortality and the drop in neonate death in 2006, pupal mortality replaced the latter as the primary contributor to generational mortality in the final year.

In virtually all cases, leek moth mortality was attributed to unknown causes. While generalist predators have been observed feeding on leek moth eggs and pupae in the field, it was rarely possible to accurately identify the cause of death for these stages. Among the larval instars, very few cadavers were recovered, making disappearance the primary factor behind larval loss. It was not clear what led to the separation of larvae from their host plants and the probability of subsequent survival and successful relocation of a suitable host plant is also not known. There was almost no apparent mortality caused by parasitoids in this life table study. At all three sites and over all three years, no egg or pupal parasitoids were reared from the sentinel leek moth specimens. Although larval parasitism was detected, it consisted of only two parasitised larvae: one second and one third instar. Both incidences occurred on exposed leeks at site $C$ in 2004 and involved the same parasitoid species, Diadegma chrysostictos (Gmelin) (Hymenoptera: Ichneumonidae).

\section{Natural enemy impact}

Figure 2 illustrates the comparison of mortality on caged and uncaged leeks for each of the three years (sites are once again pooled). In most cases, there were no statistically significant differences between treatments even though stage-specific mortality was greater on exposed than on caged leeks in 21 of the 24 comparisons. The pupa was the only stage to have significantly greater mortality on exposed plants in every year. Other stages where significant differences were detected between caged and uncaged plants were the fourth instar in 2004 and neonate and first instar in 2005. While not statistically significant, there were substantial differences in egg stage mortality in 2004 and 2006 $(P=0.053$ and $P=0.069$, respectively).

\section{Potential and realised fecundity}

Under optimal conditions in the laboratory, leek moth females laid means of $349.8 \pm 10.7$ (SE) $(n=50), 297.0 \pm 26.9$ $(n=15)$ and 322.6 $\pm 27.0 \quad(n=23)$ eggs in 2004, 2005 and 2006, respectively. These inter-annual differences were not statistically significant $(\mathrm{F}=1.19, P=0.311)$. The maximum potential fecundity observed in each year was 519, 429 and 507 eggs, respectively. Oviposition by leek moth under field conditions was substantially reduced. The maximum realised fecundity observed was 271, 264 and 293 eggs, in 2004, 2005 and 2006, respectively. On average, females in the field laid $101.4 \pm 8.0 \quad(n=30), 107.8 \pm 14.8 \quad(n=32)$ and $115.8 \pm 20.5(n=25)$ eggs, respectively. The differences in realised fecundity between years were not statistically significant $(F=0.19, P=0.831)$. In contrast, the difference between potential and realised fecundity was highly significant within each year (2004: $F=11.74, P=0.001 ; 2005$ : $\mathrm{F}=46.46, P<0.001 ; 2006: \mathrm{F}=33.18, P<0.001)$. Comparisons of potential and realised fecundity show that only $28.9 \%, 36.3 \%$ and $35.9 \%$ of available eggs were successfully laid in the field in 2004, 2005 and 2006, respectively. As shown in tables 1-3, this lost fertility accounts for $15.9-20.3 \%$ of generational mortality. While leek moth fecundity remained fairly constant during this three-year study, the variability in pre-imaginal mortality rates led to quite different outcomes in terms of population dynamics. In both 2004 and 2005, the third generation population declined $\left(R_{0}=0.185\right.$ and 0.502 , respectively) whereas it would have doubled in 2006 $\left(R_{0}=2.095\right)$. 


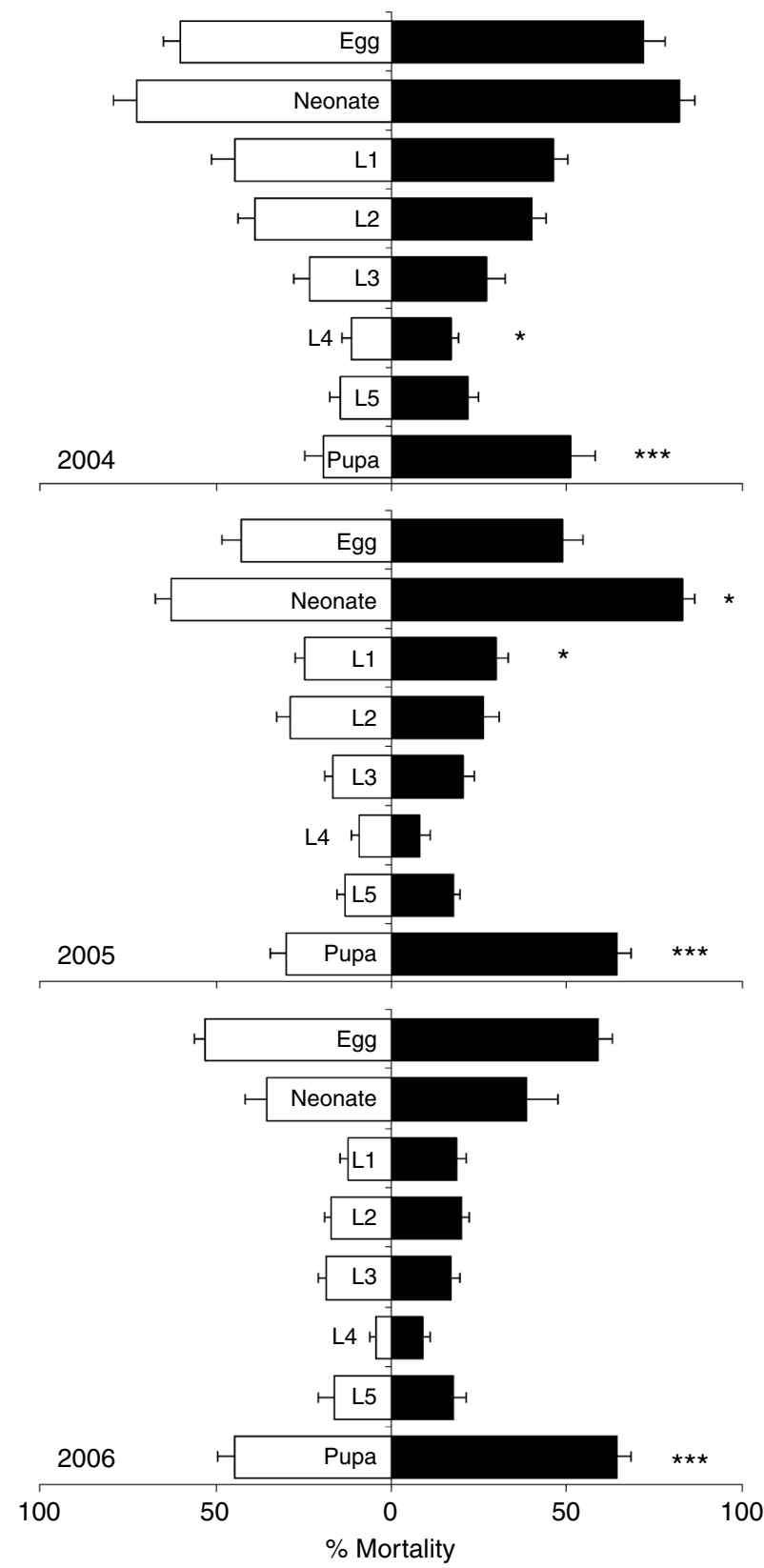

Fig. 2. Comparison of stage-specific Acrolepiopsis assectella mortality between caged (white bars) and uncaged (black bars) infested leeks. Error bars show 1 SE $(n=5$ for each life stage in each site in each year). Asterisks denote life stages where treatment significantly affected mortality (Wilcoxon pairedsample test: $\left.{ }^{*}, P<0.05 ;{ }^{* * *}, P<0.001\right)$.

\section{Key factor analysis}

The graphic approach of Varley \& Gradwell (1960) did not prove effective for identifying key mortality factors. On the other hand, regressing $k$-values against $K$ gave strong evidence that mortality during neonate establishment $\left(k_{2}\right)$ and the combined larval instars $\left(k_{3}\right)$ are key elements driving population changes in this study system. These two factors showed significant correlation to total mortality and had the highest slopes (table 4). To test whether the correlation between the combined larval $k$-values and $K$ was largely due to a particular instar, the five instars were re-analysed independently. This second analysis showed that the first instar was chiefly responsible $\left(k_{3(1)}=0.187\right)$, but as this regression coefficient is only half that for all larval instars combined, it is clearly not the only instar of influence.

\section{Discussion}

Life tables have been heavily employed in insect ecology, as they are effective tools for measuring inter- and intragenerational population change and for quantifying the impact of specific mortality factors (Harcourt, 1969; Bellows et al., 1992; Carey, 2001). This study compared stage-specific mortality rates of leek moth and, thereby, identified mortality of key stages that may contribute to the general suppression of central European leek moth populations. A life table study had been conducted with leek moth in England 30 years previously (Noyes, 1974), and a number of interesting comparisons can be made. The current study is similar to that of Noyes (1974) because both sampled specimens from artificial infestations in leek fields during the latter part of the growing season. However, they differ in that while we used fresh cohorts of insects for each life stage, the earlier study sampled from a single, continuous cohort. Furthermore, while we conducted the study at three sites over three years, Noyes (1974) limited his study to a single site and year.

We found that variation in mortality values was greater among years than among sites, however the site-specific survivorship curves (fig. 1) are relatively consistent and there is a distinct pattern to the distribution of mortality across all pre-imaginal life stages (fig. 2). In his life table study, Noyes (1974) observed a different mortality trend, with the bulk of generational mortality occurring in the final pre-imaginal stages. He recorded extremely low egg and larval mortality (3\% and 7\%, respectively), whereas our results showed egg mortality rates between $49 \%$ and $72 \%$ and mortality for the entire larval period ranging from $60 \%$ to $85 \%$. Another discrepancy between these two studies is that while we found increased survival of certain life stages within the exclusion cages, Noyes (1974) detected no cage treatment effect. Such incongruity between studies, or even between life tables within a single study, is not uncommon (e.g. Rausher, 1979; Kuhlmann et al., 1998; Furlong et al., 2004; Naranjo \& Elsworth, 2005; Toepfer \& Kuhlmann, 2006) and should perhaps be expected, given regional idiosyncrasies and environmental stochasticity (Cornell \& Hawkins, 1995). Hence, to ensure robust mortality estimates, it is important to obtain life table data from multiple sites and generations (Morris, 1955). Thus, single-sample life tables should be interpreted with extreme caution. Even with adequate replication, there is no guarantee that inferences drawn from a particular life table would be applicable to insect systems several years later or outside the original study region.

Although it is well-known that newly hatched larvae of both endophytic and exophytic species are generally very vulnerable to numerous mortality factors (Zalucki et al., 2002), relatively few studies have closely assessed the mortality occurring between egg hatch and the establishment of a feeding site by neonate larvae. Published examples 
Table 4. Key factor analysis of mortality factors affecting Acrolepiopsis assectella populations at three sites between 2004 and 2006 using regression techniques as described by Podoler \& Rogers (1975).

\begin{tabular}{lcc}
\hline $\begin{array}{l}\text { Mortality } \\
\text { factor }(k)\end{array}$ & $\begin{array}{c}\text { Regression } \\
\text { coefficients }(b)\end{array}$ & $\begin{array}{c}\text { Determination } \\
\text { coefficients }\left(r^{2}\right)\end{array}$ \\
\hline$k_{1}$ & 0.061 & 0.024 \\
$k_{2}$ & 0.545 & 0.653 \\
$k_{3}$ & 0.364 & 0.794 \\
$k_{3(1)}$ & 0.187 & 0.867 \\
$k_{3(2)}$ & 0.083 & 0.381 \\
$k_{3(3)}$ & 0.042 & 0.182 \\
$k_{3(4)}$ & 0.031 & 0.193 \\
$k_{3(5)}$ & 0.022 & 0.066 \\
$k_{4}$ & -0.025 & 0.001 \\
$k_{5}$ & 0.055 & 0.048 \\
\hline
\end{tabular}

$k_{1}$, egg; $k_{2}$, establishing neonates; $k_{3}$, combined larval instars; $k_{3(1)}, 1$ st instar; $k_{3(2)}, 2$ nd instar; $k_{3(3)}$, 3rd instar; $k_{3(4)}$, 4 th instar; $k_{3(5)}, 5$ th instar; $k_{4}$, pupa; $k_{5}$, lost fertility.

do exist (e.g. Lee, 1988; Furlong et al., 2004); however, deaths in this phase are most often included in a total value for first instar mortality. For tissue-mining species, like leek moth, whose eggs are laid on the surface of the plant, the time between hatch and plant penetration may be one of the few, or only, moments when the larvae are exposed on the exterior surface of the host plant. While there are some exceptions, for example, when neonate larvae burrow into the plant directly below the egg (Martin, 1956; Cappuccino, 1991), most species have a pre-feeding wandering phase following egg hatch (Zalucki et al., 2002). This post-hatch roaming behaviour is common in leek moth (Noyes, 1974); however, it was not previously known how the short but hazardous period affects leek moth survival.

Our study convincingly demonstrates the importance of this very brief juncture in the leek moth life cycle. Neonate mortality was largely responsible for the high generational mortality in 2004 and 2005. Then, in 2006 when this mortality value dropped by more than half from previous estimates, the overall pre-imaginal survivorship soared. On average among the three sites, eggs laid in 2006 were ten times more likely to survive to the adult stage than those laid in 2004. Such a shift in survivorship would have dramatic consequences for population dynamics. This effect was detected in the key factor analysis, which ranked neonate mortality as the primary key factor influencing population change. Considering that neonates may take approximately two hours to penetrate a leek leaf (W. Jenner, unpublished data), this is a remarkably short period for the consequences it can have on population dynamics. Although we did not observe newly hatched larvae being killed by natural enemies that would be suitable for classical biological control, this phase of the leek moth life cycle would be worth investigating further for alternative control measures. Presumably, increasing the time required by larvae to enter the leaf tissues would increase the risk of mortality. Tactics, such as plant breeding or mechanical measures to dislodge wandering larvae, might be the most realistic for targeting this stage.

By separating the leek moth larval instars, we have claimed that no specific instar was a key contributor to total mortality. However, total larval mortality was one of the major mortality factors during leek moth development. This agrees with the outcome of the key factor analysis. In a similar example involving an endemic New Zealand butterfly, larval mortality at first appears relatively insignificant when the instars are considered independently (Barron et al., 2003). Nonetheless, once the five instars were pooled, larvae accounted for nearly half of the generational mortality.

The high overall larval mortality in our study was contrary to our expectations. We had anticipated this stage to experience the greatest survival since the larvae feed within a structural refuge, whereas the eggs and pupae are fully exposed on the external plant surface. Meta-analyses comparing survivorship in species with different feeding habits have shown that exophytic species tend to experience greater pre-adult mortality than endophytic species (Price, 1975; Cornell \& Hawkins, 1995). It is possible that this acrossspecies generalisation is not a good predictor of withinspecies mortality distribution when certain life stages are endophytic and others are exophytic. Interestingly, there are no equivalent syntheses that attempt to elucidate patterns of stage-specific mortality rates within single species that have variable degrees of concealment during their pre-imaginal development. In many herbivorous insect species, the level of concealment within host plant tissues or surrounding substrates changes as individuals progress from one life stage to the next. As a case in point, leek moth would fall into the endophyte group under the traditional system of categorisation because all larval instars are leaf miners. The problem with this classification is immediately apparent as immature leek moths are actually on the exterior of their host plant during the egg, neonate and pupal phases, all of which contribute significantly to generational mortality. Particularly for species that suffer high levels of egg and pupal mortality, it is likely inappropriate to class them as strictly endophytic or exophytic based on the degree of concealment of the larval stage.

Kyi et al. (1991) remarked that life table studies often fail to identify causes of observed mortality. Over the last two decades, life tables have continued to play a key role in insect ecology; and many of these studies clearly distinguish between specific mortality factors (e.g. Floater \& Zalucki, 1999; Barron et al., 2003; Girardoz et al., 2007; Pereira et al., 2007) owing to the development of improved experimental and sampling techniques (Luck et al., 1988; Bellows et al., 1992). Nonetheless, unassigned mortality is still commonplace in even the most recent insect life tables, suggesting that significant hurdles still remain in assessing field mortality. Based on 124 herbivore life tables, Cornell et al. (1998) calculated an average of approximately $20 \%$ mortality due to unknown factors over all stages. Although the current study obtained little information on specific mortality factors for each life stage, the comparison of mortality rates on caged and uncaged leeks serves as a first step in quantifying the relative contribution of natural enemies. As illustrated in fig. 2, there was substantial mortality even in the exclusion treatments, particularly during the egg and neonate stages where mean mortality for each was approximately $50 \%$. For eclosing first instar larvae, plant factors may have played a key role, while inclement weather was very likely a cause of mortality among both eggs and neonate larvae. Localised rain showers were a common phenomenon during the trial period in 2004 and 2005, but less so in 2006. This may have contributed to the higher neonate mortality in the first two 
years. Simple observations of establishing neonates have shown that, while on the leaf surface, these tiny larvae are easily dislodged, suggesting that light wind or rain would be lethal if it coincided with egg hatch. The survival probability for newly hatched larvae that become separated from their host plants is poorly understood, but is generally assumed to be very low (Zalucki et al., 2002). Dislodgement can even be costly for leek moth larvae that remain on the plant because they often tumble into the leaf axils where rainwater collects. While more mature larvae have been seen to pull themselves out of these pools, neonate larvae are especially vulnerable to drowning.

The apparent lack of parasitism in this study matches Noyes' (1974) observations but was not expected as there are a number of published accounts of leek moth parasitoids in continental Europe. These include both larval and pupal parasitoids (Frediani, 1954; Labeyrie, 1966; Plaskota \& Dabrowski, 1986); but, to our knowledge, there are no records of egg parasitism. Previous descriptions of parasitism have typically come from locations with sustained leek moth outbreaks, whereas natural populations in Switzerland during our study were generally so low that it was not possible to detect plant damage, much less to sample naturally occurring individuals. This low host abundance may have led to such significant numerical reductions of parasitoids that they were difficult to detect using small experimental populations of leek moth placed within relatively large commercial fields. Furthermore, most of the described parasitoids of leek moth are polyphagous species, and these generalist foragers have been shown to undergo shifts in host preference in response to changes in the relative abundance of host species (Cornell \& Pimentel, 1978; Duan et al., 2000). Hence, this life table study likely underestimates the average contribution of both specific and generalist natural enemies to leek moth mortality. In support of this suggestion, several parasitoids were reared from leek moth larvae and pupae collected in 2005 from a newly discovered Swiss field site that had an economically critical leek moth population (Jenner, 2008). Parasitoids, therefore, may play a more significant role in larger leek moth populations where host cues are more easily detected.

Alternatively, the lack of parasitism in this study may have resulted from an unanticipated trend of declining parasitism towards the end of the growing season. Repeated random samples of larvae and pupae from the high-density field site described above showed diminishing parasitism rates from mid- to late-summer, such that only one species of pupal parasitoid was obtained in the final generation (Jenner, 2008). Shifts in parasitoid community structure across generations are not uncommon and have already been described for leek moth by Plaskota \& Dabrowski (1986). However, it is interesting to note that those authors depicted an increase in parasitoid-induced mortality with each subsequent generation, and this was the basis for our selection of the third generation for the life table study. Due to this potential temporal variation in community structure, early generation parasitism of leek moth may be more apparent, even at low density sites, but this has yet to be tested. Until more is known, mortality patterns from the third generation should not be assumed to reflect those of earlier generations. Thus, this study has identified some, but possibly not all, of the key mortality processes that contribute to limiting leek moth populations in central Europe.
Owing to the lack of parasitoids emerging from fieldexposed leek moths, predation is believed to have been the primary form of natural enemy-induced mortality in this study. The greatest and most consistent differences in mortality between caged and exposed leeks were observed for the pupae, suggesting that this stage is particularly vulnerable to predators. Indeed, leek moth pupae tend to be very exposed on the leaf surface and mirid and anthocorid bugs and chrysopid larvae were occasionally seen feeding on them during this study. There were no apparent signs of pathogen-related mortality in any leek moth life stages, and this is perhaps not surprising given that diseases tend not to be important factors in leaf-mining species (Auerbach et al., 1995). It is possible, however, that the use of leeks and insects reared under controlled conditions may have played a role in reducing the incidence of pathogenesis.

In conclusion, this study of the third and final leek moth generation found a propensity for higher mortality in the exposed egg and pupal stages compared to the individual leaf-mining larval stages. However, when instars were pooled, larval mortality nearly always exceeded that of eggs and pupae. We also demonstrated a life table study approach that provided the resolution necessary to uncouple mortality associated with neonate establishment from that which occurs after successful establishment on the host plant. In doing so, we revealed that an important fraction of generational mortality occurs in the brief period of exposure following egg hatch. Now that this critical stage has been identified, it would be possible to conduct experiments that focus on the specific factors causing the high neonate mortality. The study also showed that while natural enemies appeared to have only a transient effect on leek moth egg and larval survival, they were a consistent and significant factor in pupal mortality. Similar conclusions were derived from concurrent field surveys in 2005 at a collection site with a high natural leek moth population, where pupal parasitoids were frequently obtained. The observation that the pupal stage is particularly vulnerable to natural enemies suggests that it may be the best target for classical biological control in Canada. A logical follow-up to this study would be a similar evaluation of pre-imaginal leek moth mortality during earlier generations as well as in its introduced range in Canada. This would facilitate a better understanding of why Canadian leek moth populations appear to reach higher densities.

\section{Acknowledgements}

The authors are indebted to Lars Andreassen, Serge Hämmerli, Emma Hunt, Virginia Larraz, Alicia Leroux, Kathy Makela, Jake Miall, C-Jae Morden and Basri Pulaj for their valuable assistance in the field and laboratory. Further thanks go to our Swiss agricultural collaborators: Rolf Etter (Bioleguma, Ried near Kerzers), Roland Fasnacht (Bio Gemüse, Sugiez), Stefan Müller (BioLand Agrarprodukte AG, Steinmaur), Dieter Schächtle (Bio-Gemüsebau, Taegerwilen) and Jürg \& Erwin Züttel (Gemüse, Müntschemier).

\section{References}

Allison, J., Jenner, W., Cappuccino, N. \& Mason, P.G. (2007) Oviposition and feeding preference of Acrolepiopsis assectella Zell. (Lep., Acrolepiidae). Journal of Applied Entomology 131, 690-697. 
Auerbach, M.J., Connor, E.F. \& Mopper, S. (1995) Minor miners and major minors: population dynamics of leaf-mining insects. pp. 83-110 in Cappuccino, N. \& Price, P.W. (Eds) Population Dynamics: New Approaches and Synthesis. San Diego, CA, Academic Press.

Barron, M.C., Barlow, N.D. \& Wratten, S.D. (2003) Non-target parasitism of the endemic New Zealand red admiral butterfly (Bassaris gonerilla) by the introduced biological control agent Pteromalus puparum. Biological Control 27, 329335.

Bellows Jr., T.S., Van Driesche, R.G. \& Elkinton, J.S. (1992) Life-table construction and analysis in the evaluation of natural enemies. Annual Review of Entomology 37, 587614.

Cappuccino, N. (1991) Mortality of Microrhopala vittata (Coleoptera: Chrysomelidae) in outbreak and nonoutbreak sites. Environmental Entomology 20, 865-871.

Carey, J.R. (2001) Insect biodemography. Annual Review of Entomology 46, 79-110.

Cornell, H.V. \& Hawkins, B.A. (1995) Survival patterns and mortality sources of herbivorous insects: some demographic trends. The American Naturalist 145, 563-593.

Cornell, H.V. \& Pimentel, D. (1978) Switching in the parasitoid Nasonia vitripennis and its effects on host competition. Ecology 59, 297-308.

Cornell, H.V., Hawkins, B.A. \& Hochberg, M.E. (1998) Towards an empirically-based theory of herbivore demography. Ecological Entomology 23, 340-349.

Debach, P. \& Rosen, D. (1991) Biological Control by Natural Enemies. 465 pp. Cambridge, Cambridge University Press.

Duan, J.J., Messing, R.H. \& Dukas, R. (2000) Host selection of Diachasmimorpha tryoni (Hymenoptera: Braconidae): comparative response to fruit-infesting and gall-forming tephritid flies. Environmental Entomology 29, 838-845.

Elkinton, J.S., Buonaccorsi, J.P., Bellows Jr., T.S. \& Van Driesche, R.G. (1992) Marginal attack rate, k-values and density dependence in the analysis of contemporaneous mortality factors. Researches on Population Ecology 34, 29-44.

Elton, C.S. (1958) The Ecology of Invasions by Animals and Plants. 181 pp. London, Chapman and Hall.

Floater, G.J. \& Zalucki, M.P. (1999) Life tables of the processionary caterpillar Ochrogaster lunifer Herrich-Schäffer (Lepidoptera: Thaumetopoeidae) at local and regional scales. Australian Journal of Entomology 38, 330-339.

Frediani, D. (1954) Ricerche morfo-biologiche sull'Acrolepia assectella Zell. (Lep. Plutellidae) nell'Italia centrale. Redia 39, 187-249.

Furlong, M.J., Shi, Z., Liu, S. \& Zalucki, M.P. (2004) Evaluation of the impact of natural enemies on Plutella xylostella L. (Lepidoptera: Yponomeutidae) populations on commercial brassica farms. Agricultural and Forest Entomology 6, 311322.

Girardoz, S., Tomov, R., Eschen, R., Quicke, D.L.J. \& Kenis, M. (2007) Two methods of assessing the mortality factors affecting the larvae and pupae of Cameraria ohridella in the leaves of Aesculus hippocastanum in Switzerland and Bulgaria. Bulletin of Entomological Research 97, 445-453.

Harcourt, D.G. (1969) The development and use of life tables in the study of natural insect populations. Annual Review of Entomology 12, 175-196.

Jary, S.G. \& Rolfe, S.W. (1945) The leek moth. Agriculture 52, 35-37.

Jenner, W.H. (2008). Evaluation of a candidate classical biological control agent and critical assessment of suggested host specificity testing guidelines. PhD thesis, Carleton University, Ottawa, ON, Canada.

Jenner, W.H. \& Kuhlmann, U. (2005) Biological control of leek moth, Acrolepiopsis assectella. Annual Report 2004/2005. 13 pp. Delémont, CABI Europe - Switzerland.

Kuhlmann, U., Carl, K.P. \& Mills, N.J. (1998) Quantifying the impact of insect predators and parasitoids on populations of the apple ermine moth, Ypnomeuta malinellus (Lepidoptera: Yponomeutidae), in Europe. Bulletin of Entomological Research 88, 165-175.

Kyi, A., Zalucki, M.P. \& Titmarsh, I.J. (1991) An experimental study of early stage survival of Helicoverpa armigera (Lepidoptera: Noctuidae) on cotton. Bulletin of Entomological Research 81, 263-271.

Labeyrie, V. (1966) Sous-famille des Acrolepiinae. pp. 233-249 in Balachowsky, A.S. (Ed.). Entomologie Appliquée à l'Agriculture. Tome II, Lépidoptères, Vol. 1. Paris, Masson et Cie.

Landry, J.-F. (2007) Taxonomic review of the leek moth genus Acrolepiopsis (Lepidoptera: Acrolepiidae) in North America. Canadian Entomologist 139, 319-353.

Lee, D.A. (1988) Factors affecting mortality of the European corn borer, Ostrinia nubilalis (Hubner), in Alberta. Canadian Entomologist 120, 841-853.

Luck, R.L., Shepard, B.M. \& Kenmore, P.E. (1988) Experimental methods for evaluating arthropod natural enemies. Annual Review of Entomology 33, 367-391.

Markula, M. (1981) Pests of cultivated plants in Finland in 1980. Annales Agriculturae Fenniae 20, 25-27.

Martin, J.L. (1956) The bionomics of the Aspen Blotch Miner, Lithocolletis salicifoliella Cham. (Lepidoptera: Gracillaridae). Canadian Entomologist 88, 155-169.

Mason, P.G., Appleby, M., Callow, K., Allen, J., Fraser, H. \& Landry, J.-F. (2006) Leek moth Acrolepiopsis assectella (Lepidoptera: Acrolepiidae) a pest of Allium spp.: biology and minor use insecticide registration. Final Project Report to 'Improving Farming Systems Program', AAFC Pest Management Centre (15 May 2006).

Morris, R.F. (1955) The development of sampling techniques for forest insect defoliators, with particular reference to the spruce budworm. Canadian Journal of Zoology 33, 225-294.

Morris, R.F. (1959) Single-factor analysis in population dynamics. Ecology 40, 580-588.

Naranjo, S.E. \& Ellsworth, P.C. (2005) Mortality dynamics and population regulation in Bemisia tabaci. Entomologia Experimentalis et Applicata 116, 93-108.

Noyes, J.S. (1974) The biology of the leek moth, Acrolepia assectella (Zeller). PhD thesis, University of London, London, UK.

Nyrop, J.P., Shelton, A.M. \& Theunissen, J. (1989) Value of a control decision for leek moth infestations in leek. Entomologia Experimentalis et Applicata 53, 167-176.

Pereira, E.J.G., Picanço, M.C., Bacci, L., Crespo, A.L.B. \& Guedes, R.N.C. (2007) Seasonal mortality factors of the coffee leafminer, Leucoptera coffeella. Bulletin of Entomological Research 97, 421-432.

Plaskota, E. \& Dabrowski, Z.T. (1986) Biological principles of leek moth (Acrolepiopsis assectella Zeller, Lepidoptera: Plutellidae) control. I. Host plants, damage caused by leek moth larvae, and leek moth parasites. Annals of Warsaw Agricultural University 13, 27-34.

Podoler, H. \& Rogers, D. (1975) A new method for the identification of key factors from life-table data. Journal of Animal Ecology 44, 85-114. 
Price, P.W. (1975) Insect Ecology 514 pp. New York, John Wiley \& Sons.

Rausher, M.D. (1979) Larval habitat suitability and oviposition preference in three related butterflies. Ecology 60, 503-511.

SPSS Inc. (2005) SPSS Base 14.0 User's Guide. Chicago, SPSS Inc.

Thibout, E. \& Nowbahari, B. (1987) La selection du lieu de nymphose chez la teigne du poireau, Acrolepiopsis assectella (Lep.): déterminisme exogène et variations interpopulations. Annales de la Société Entomologique de France 23, 183-192.

Toepfer, S. \& Kuhlmann, U. (2006) Constructing life-tables for the invasive maize pest Diabrotica vergifera vergifera
(Col.; Chrysomelidae) in Europe. Journal of Applied Entomology 130, 193-205.

Van Driesche, R.G. \& Bellows Jr., T.S. (1996) Biological Control. 560 pp. New York, Chapman and Hall.

Varley, G.C. \& Gradwell, G.R. (1960) Key factors in population studies. Journal of Animal Ecology 29, 399-401.

Velitchkevitch, A.I. (1924) Biological observations on $A$. assectella, Zell. in the Novgorod government [abstract]. Review of Applied Entomology 12, 356.

Zalucki, M.P., Clarke, A.R. \& Malcolm, S.B. (2002) Ecology and behaviour of first instar larval Lepidoptera. Annual Review of Entomology 47, 361-393. 